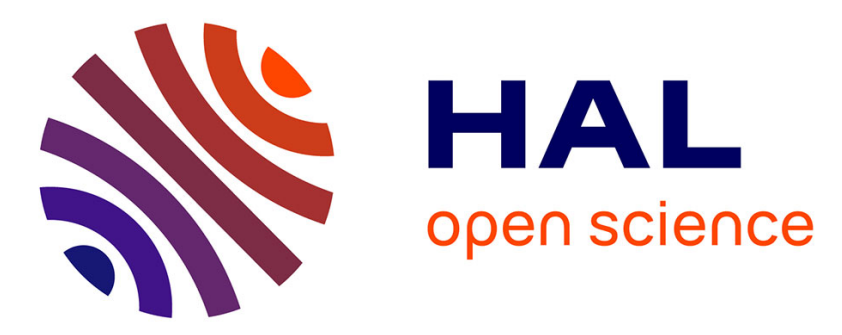

\title{
Coupled thermal fluctuations of proteins and protein hydration water on the picosecond timescale.
}

Alessandro Paciaroni, Andrea Orecchini, Elena Cornicchi, Matteo Marconi, Caterina Petrillo, Francesco Sacchetti, Michael Haertlein, Martine Moulin

\section{- To cite this version:}

Alessandro Paciaroni, Andrea Orecchini, Elena Cornicchi, Matteo Marconi, Caterina Petrillo, et al.. Coupled thermal fluctuations of proteins and protein hydration water on the picosecond timescale.. Philosophical Magazine, 2008, 88 (33-35), pp.4071-4077. 10.1080/14786430802464263 . hal-00513973

\section{HAL Id: hal-00513973 \\ https://hal.science/hal-00513973}

Submitted on 1 Sep 2010

HAL is a multi-disciplinary open access archive for the deposit and dissemination of scientific research documents, whether they are published or not. The documents may come from teaching and research institutions in France or abroad, or from public or private research centers.
L'archive ouverte pluridisciplinaire HAL, est destinée au dépôt et à la diffusion de documents scientifiques de niveau recherche, publiés ou non, émanant des établissements d'enseignement et de recherche français ou étrangers, des laboratoires publics ou privés. 


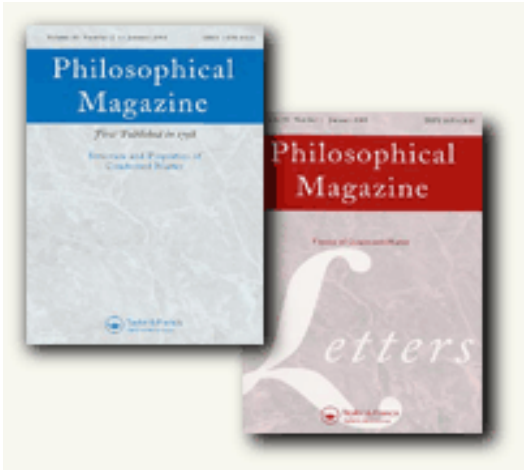

\section{Coupled thermal fluctuations of proteins and protein hydration water on the picosecond timescale.}

\begin{tabular}{|r|l|}
\hline Journal: & Philosophical Magazine \& Philosophical Magazine Letters \\
\hline Manuscript ID: & TPHM-08-May-0153.R1 \\
\hline Journal Selection: & Philosophical Magazine \\
\hline Author: & 26-Jun-2008 \\
\hline & $\begin{array}{l}\text { Complete List of Authors: } \\
\text { Parconi, Matteo; University of Perugia, Physics } \\
\text { Petrillo, Caterina; università di perugia, physics } \\
\text { Sacchetti, Francesco; università degli studi di perugia, } \\
\text { dipartimento di fisica } \\
\text { haertlein, michael; Institut Laue Langevin } \\
\text { moulin, martine; Institut Laue Langevin }\end{array}$ \\
\hline Keywords: & $\begin{array}{l}\text { biomolecules, biophysics, glass transition, neutron scattering, } \\
\text { proteins }\end{array}$ \\
\hline Keywords (user supplied): & $\begin{array}{l}\text { hydration water, mean square displacements, dynamical } \\
\text { transition }\end{array}$ \\
\hline &
\end{tabular}

\section{scholarONE" \\ Manuscript Central}




\begin{abstract}
The mean square displacements (MSD) of a model protein, the Maltose Binding Protein, and its hydration water have been estimated by the elastic neutron scattering intensity measured on the time-of-flight spectrometer IN5. The availability of the protein in both fully deuterated and hydrogenated form allowed us to reliably separate the contribution of the solvent interacting with biomolecule from the one of the hydrated biomolecule. The thermal fluctuations of hydration water and protein activate in the same temperature range $200-220 \mathrm{~K}$. This result supports a picture where the dynamical coupling between the biomolecule and the solvent is already effective in the picosecond timescale. A quantitative agreement of the MSD with the values from molecular dynamics simulations is found.
\end{abstract}




\section{Introduction}

Water plays a major role in determining and modulating the stability and function of biological macromolecules. This vital role is played through the peculiar action of hydration water in affecting both structure and dynamics of proteins and nucleic acids. For example, water molecules around hydrophobic and hydrophilic sites are important to settle the activity of enzyme proteins [1-3] and are part of the recognition process by other molecules or proteins. With this respect, the properties of water molecules in the immediate vicinity of the protein surface deserve particular attention as they are particularly relevant to the function [4]. Despite a large number of theoretical and experimental studies [5-13], there is no generalized picture of the dynamics of hydration water at the local molecular level yet. In fact, a detailed picture of the vibrational and diffusive motions of water molecules would shed light on the mechanisms through which they are coupled with biomolecules. Such a coupling is quite evident even in the most intriguing phenomenon which characterises the dynamics of proteins in the picosecond timescale, the so-called "dynamical transition". This event, which consists in the activation above 200-220K of large-amplitude anharmonic protein internal motions, is well visible in hydrated biomolecules whereas it cannot be detected in dry systems [14-18]. It has been proposed that the protein dynamical transition does not correspond to a real "transition", but it is likely the signature of the onset of the conformational mean square displacements (MSD) [19]. The existence of an intimate dynamical coupling between a biomolecule and its surrounding environment has been widely studied even for non-aqueous solvents [20-26].

In the present work we investigate the extent of thermal fluctuations in the hydration water of a fully deuterated (perdeuterated) protein, the Maltose Binding Protein (MBP), a model system often used for biotechnological purposes [27]. The exploitation of a perdeuterated protein, which has a low scattering power with respect to the hydrogen atoms of hydration water, allowed us to singleout the hydration water MSD on the spectrometer IN5 (ILL, Grenoble), i.e. on the pico- and subpicosecond timescale, with an unprecedented accuracy. We thus provide evidence of a common dynamical onset of the thermal fluctuations in the MBP and its hydration water.

\section{Materials and Methods}

\subsection{Samples preparation}

Maltose binding protein in its hydrogenated $(\mathrm{MBP}(\mathrm{H}))$ and perdeuterated form $(\mathrm{MBP}(\mathrm{D}))$, was provided by the ILL-EMBL Deuteration Laboratory (D-Lab) in Grenoble. In the adopted protocol, MBP was produced as a histidine tagged fusion protein, which allowed its purification by immobilized metal-ions affinity chromatography (IMAC) in a one step procedure. Then, both the hydrogenated and the perdeuterated form of this protein were expressed in high-cell density cultures [28] and purified. Thanks to such a procedure a noticeable amount $(\sim 200 \mathrm{mg})$ of both $\mathrm{MBP}(\mathrm{H})$ and $\mathrm{MBP}(\mathrm{D})$ was made available. The samples were left for 3 days in solution of respectively $\mathrm{D}_{2} \mathrm{O}$ and $\mathrm{H}_{2} \mathrm{O}$ to exchange most of the labile hydrogen/deuterium atoms. Then, the solutions were dialysed twice against the buffer, lyophilised and finally dried under vacuum, in the presence of $\mathrm{P}_{2} \mathrm{O}_{5}$. The $\mathrm{MBP}(\mathrm{H})$ and $\mathrm{MBP}(\mathrm{D})$ powder samples were then hydrated by $\mathrm{D}_{2} \mathrm{O}$ and $\mathrm{H}_{2} \mathrm{O}$ vapour pressure up to a hydration degree of $0.42 h$ and $0.37 h$ respectively ( $h=$ grams of water/grams dry protein), in order to have the same number of water molecules per protein.

\subsection{Incoherent neutron scattering}

Thermal neutrons are powerful and widely used probes to directly obtain information on the fast motions (nano- and pico-seconds characteristic times) of biological samples. Neutrons exchange 
with the sample nuclei a momentum $\hbar \boldsymbol{Q}$ and an amount of energy $E=\hbar \omega$ with a probability given by the dynamical structure factor $S(Q, E)$.

Within the incoherent approximation, the signal of the $\mathrm{MBP}(\mathrm{H})+\mathrm{D}_{2} \mathrm{O}$ sample comes mainly from the non-exchangeable protein hydrogen atoms, while the spectrum of the $\mathrm{MBP}(\mathrm{D})+\mathrm{H}_{2} \mathrm{O}$ is composed respectively by the contribution from the hydration water $(\sim 72 \%)$ and the exchangeable protein hydrogens $(\sim 28 \%)$.

In order to extract the contribution coming solely from the protein hydration water, $S_{\mathrm{H}_{2} \mathrm{O}}(Q, E)$, we made the assumption that in the meV region the vibrational behaviour of the protein exchangeable hydrogen atoms is the same as the non-exchangeable ones [29]. On these bases we may write:

$$
S_{H_{2} O}(Q, E)=S_{D H}(Q, E)-0.26 \cdot S_{H D}(Q, E)
$$

where $S_{D H}(\boldsymbol{Q}, E)$ and $S_{H D}(Q, E)$ are the dynamical structure factors of respectively $\mathrm{MBP}(\mathrm{D})+\mathrm{H}_{2} \mathrm{O}$ and $\mathrm{MBP}(\mathrm{H})+\mathrm{D}_{2} \mathrm{O}$, and 0.26 is the ratio between the number of the exchanged protons and the number of non-exchangeable protons.

In this work we focus on the elastic part of the spectra. An analysis of the features of the elastic scattering $S_{\mathrm{H}_{2} \mathrm{O}}(Q, E \approx 0)$ was made within the well-known Gaussian approximation [30]:

$$
S_{\mathrm{H}_{2} \mathrm{O}}(Q, E \approx 0) \approx \exp \left(-\left\langle u^{2}\right\rangle Q^{2}\right)
$$

where $\left\langle u^{2}\right\rangle$ are the mean square displacements of the water protons. We verified that Eq. (2), which holds in the small- $Q$ region, can describe the elastic data at all the investigated temperatures.

\subsection{Neutron scattering experiment}

The incoherent neutron scattering measurements were performed on the high-flux time-of-flight spectrometer IN5 [31], at ILL. The incident wavelength $\lambda=5.2 \AA$ was employed, achieving an elastic wave-vector range $0.4 \AA^{-1}<Q<2.2 \AA^{-1}$, accessible energy transfers $E$ from $-2 k_{B} T$ to $1.5 \mathrm{meV}$ and an energy resolution with a full width at half maximum of $\sim 0.11 \mathrm{meV}$. The collected data were treated with a standard correction procedure, taking into account for empty cell contribution, transmission and non-uniform detector efficiency as a function of the scattering angle. The values of the transmission coefficients were 0.95 and 0.93 for respectively $\mathrm{MBP}(\mathrm{D})-\mathrm{H}_{2} \mathrm{O}$ and $\mathrm{MBP}(\mathrm{H})-$ $\mathrm{D}_{2} \mathrm{O}$. Multiple scattering was neglected. The samples were placed in a slab aluminium cell, at an angle of $135^{\circ}$ with respect to the incident neutron beam, and measured from 50 to $300 \mathrm{~K}$.

\section{Results and Discussion}

In Fig. 1 we plot the elastic intensities, integrated over a range of small- $Q$ values $\left(0.4 \AA^{-1}<Q<1\right.$. $\left.\AA^{-1}\right)$, as a function of the temperature, for both $\mathrm{MBP}(\mathrm{H})+\mathrm{D}_{2} \mathrm{O}$ and the protein hydration water. In the small- $Q$ limit $\left(<u^{2}(T)>Q^{2}<<1\right)$, Eq. (2) leads to $S(Q, E \approx 0)=1-<u^{2}(T)>Q^{2}$, then the departure from unity gives a measure of the mobility of the hydrogen atoms in the systems we investigated. The intensity profiles result to be noticeably dependent on the temperature, particularly above $200 \div 220 \mathrm{~K}$, where in both cases the trend clearly deviates from the almost linear behaviour at low temperature. As we mentioned in the "Introduction", for the $\mathrm{MBP}(\mathrm{H})-\mathrm{D}_{2} \mathrm{O}$ system, such onset of additional mobility over the low-temperature quasi-harmonic behaviour, is the signature of the protein dynamical transition. On the other hand, the elastic intensity of the protein hydration water displays a steep decrease occurring in the same temperature range as the hydrated protein. The depletion of elastic intensity is by far more visible for protein hydration water, thus reasonably 
indicating that, above the protein dynamical transition, the motions of water molecules on the protein surface are characterised by larger amplitudes than those of the protein atoms.

More quantitative information on the process taking place at $200 \div 220 \mathrm{~K}$ can be derived by exploiting Eq. (2) to calculate the atomic MSD of MBP, $\left\langle u^{2}\right\rangle_{M B P-I N 5}$, and its hydration water, $\left\langle u^{2}\right\rangle_{H 2 O-I N 5}$, which are shown in Fig. 2. As expected, $\left\langle u^{2}\right\rangle_{M B P-I N 5}$ and $\left\langle u^{2}\right\rangle_{\text {H2O-IN5 }}$ show a linear slow increase in the low-temperature range and a distinct departure from this trend above $200 \div 220 \mathrm{~K}$. The characteristic times of the dynamical mechanisms which contribute to such activation must be faster than around $15 \mathrm{ps}$, i.e. the inverse of the energy resolution half-width at the elastic peak (see the "Neutron scattering experiment" section). In Fig. 2 we also report the MSD of the MBP hydration water, measured instead on the neutron backscattering spectrometer IN16 and analysed within the Gaussian approximation [32]. In this case, due to the very high energy resolution $(\sim 1 \mu \mathrm{eV})$ achieved by IN16, the measured MSD arise from the average contribution of motions faster than about $1.5 \mathrm{~ns}$. This comparison allows us to extract the contribution to the MSD coming from the picosecond time-windows of IN5 with respect to the larger nanosecond and subnanosecond timescale accessible on IN16. Quite interestingly, if one looks at the MSD as estimated in both the spectrometers, the dynamical onset of the protein hydration water motions takes place at around the same temperature. This finding suggests that an important contribution to the dynamical activation of protein hydration water comes from fast motions occurring already in the picosecond timescale. On the other hand, above the dynamical activation, the extent of the water mobility is greater when it is sampled over the wide timescale of IN16, consistently with the diffusive character of the motions on the protein surface. In fact, on increasing the time-window over which the motions are observed, the water molecules may explore larger and larger space regions. It is worth of note that the MSD of water oxygen atoms calculated by molecular dynamics (MD) simulations and estimated at $\mathrm{t}=15 \mathrm{ps}$, i.e. the same timescale as IN5 [32], nicely superimpose to $\left\langle u^{2}\right\rangle_{H 2 O-I N 5}$. This agreement supports the exploitation of MD simulations to interpret our data. Actually, MD results indicate that the dynamical onset of hydration water molecules is due to translational degrees of freedom, with a diffusion rate that increases progressively with temperature. Such diffusive processes sustain an increasingly faster relaxation rate of the protein-water hydrogen-bond network, which would in turn be crucial to promote the so-called protein dynamical transition [33]. This phenomenon, which has been put in relationship with the biological functionality $[17,34,35]$, can be depicted as the onset of large-amplitude anharmonic motions, over the prevalently harmonic lowtemperature protein dynamics [14,15,17]. In fact, such a dynamical transition is well visible in the trend of the MSD of the hydrated protein alone (hydrogenated protein in $\mathrm{D}_{2} \mathrm{O}$ ). Above the dynamical transition, the protein MSD are smaller than those of hydration water, due to the structural constraints to which protein hydrogen atoms are subjected. Starting from around 180200K, the protein MSD measured on IN16 are slightly larger than those measured on IN5 (see Fig. 3 ) thus indicating that there is a not negligible contribution from fluctuations in the time-window above $15 \mathrm{ps}$ and below $1.5 \mathrm{~ns}$. Methyl group reorientations are good candidate to explain such an effect, in particular at low temperature [36].

In a number of previous works, hydrated protein powders were shown to exhibit a dynamical transition at around 200-220 K [15,17,35]. Similar values were found for hydrated DNA [18,37]. Very recently, it has been suggested that the dynamical transition of hydration water is the effect of a fragile-to-strong dynamical crossover, which is characterised by the change in the temperature dependence of quantities such as the average translational relaxation time, and corresponds to a transition in water structure from a predominantly high-density (more fluid state) to a low-density (less fluid state) form [13]. However, the intrinsic origin of the dynamical crossover of protein hydration water is still a matter of large debate, and as an alternative picture it has been proposed that the activation at $200 \div 220 \mathrm{~K}$ is not due to a true fragile-to-strong transition but rather to a vanishing of the strongly cooperative $\alpha$-relaxation, occurring in coincidence of the glass transition of the overall system [38]. In addition, dielectric spectroscopy data suggest that the relation between the secondary relaxation of the solvent and the conformation relaxation of the hydrated protein is 


\section{References}

[1] Gregory, R. B., ed. (1995) Protein-Solvent Interactions (Dekker, New York).

[2] M. F. Colombo, D. C. Rau and V. A. Parsegian, Science 256655 (1992).

[3] V. Launnas, B. M. Pettit, Proteins Struct. Funct. Genet. 18148 (1994).

[4] N. Nandi, B. Bagchi, J. Phys. Chem. B 10110954 (1997).

[5] F. T. Burling, W. I. Weis, K. M. Flaherty, A. T. Brunger Science 27172 (1996).

[6] D. I. Svergun, S. Richard, M. H. J. Koch, Z. Sayers, S. Kuprin and G. Zaccai, Proc. Natl. Acad. Sci. USA 952267 (1998).

[7] M. Gerstein and C. Chothia, Proc. Natl. Acad. Sci. USA 9310167 (1996).

[8] V. A. Makarov, M. Feig, B. Andrews and M. Pettitt, Biophys. J. 75150 (1998).

[9] X. Cheng and B. P. Schoenborn, J. Mol. Biol. 220381 (1991).

[10] W. Gu and B. P. Schoenborn, Proteins Struct. Funct. Genet. 2220 (1995).

[11] E. H. Grant, V. E. R. McClean, N. R. V. Nightingale, R. J. Sheppard and M. J. Chapman, Bioelectromagnetics 7151 (1986).

[12] O. Gottfried, L. Edvards and K. Wüthrich, Science 254974 (1991).

[13] S.-H. Chen, L. Liu, E. Fratini, P. Baglioni, A. Faraone and E. Mamontov, Proc. Natl. Acad.

Sci. USA 1039012 (2006).

[14] W. Doster, S. Cusack and W. Petry, Nature 337754 (1989).

[15] D. Ringe, G. A. Petsko, Biophys. Chem. 105667 (2003).

[16] F. Parak, Curr. Opinion. Struct. Biol. 13552 (2003).

[17] A. Paciaroni, S. Cinelli, E. Cornicchi, A. De Francesco and G. Onori, Chem. Phys. Lett. 410 400 (2005).

[18] E. Cornicchi, S. Capponi, M. Marconi, G. Onori, A. Paciaroni, Phil. Mag. 87509 (2007).

[19] P. W. Fenimore, H. Frauenfelder, B. H. McMahon and R. D. Young, Proc. Natl. Acad. Sci. USA. 10114408 (2004).

[20] J. E. Curtis, T. E. Dirama, G. A. Carri and D. J. Tobias, J. Phys. Chem. B. 11022953 (2006).

[21] A. Paciaroni, S. Cinelli and G. Onori, Biophys. J. 831157 (2002).

[22] E. Cornicchi, G. Onori and A. Paciaroni, Phys. Rev. Lett. 95158104 (2005).

[23] G. Caliskan, R. M. Briber, D. Thirumalai, V. Garcia-Sakai, S. A. Woodson and A. P. Sokolov, J. Am. Chem. Soc. 12832 (2005).

[24] E. Cornicchi, M. Marconi, G. Onori and A. Paciaroni, Biophys. J. 91289 (2006). 
[25] E. Cornicchi, S. Capponi, M. Marconi, G. Onori, A. Paciaroni, Eur. Biophys. J., in press. [26] E. Cornicchi, A. De Francesco, M. Marconi, G. Onori and A. Paciaroni, Chem. Phys. 345219 (2008).

[27] I. L. Medintz and J. R. Deschamps, Curr. Opin. Biotech. 1717 (2006).

[28] L. Di Costanzo, M. Moulin, M. Haertlein, F. Meilleur, D.W. Christianson, Arch. Biochem. Biophys. 46582 (2007).

[29] M. Tarek, and D. J. Tobias, J. Chem. Phys. 115, 1607 (2001).

[30] M. Bée, Quasielastic Neutron Scattering (Adam Hilger, Bristol and Philadelphia) (1988).

[31] Website : http://www.ill.eu/in5/home

[32] K. Wood, A. Frölich, A. Paciaroni, M. Moulin, M. Härtlein, G. Zaccai, D. J. Tobias and M.

Weik, J. Am. Chem. Soc. 1304586 (2008).

[33] M. Tarek and D.J Tobias, Phys. Rev. Lett. 89275501 (2002).

[34] G. Zaccai, Science 2881604 (2000).

[35] W. Doster and M. Settles, Biochim. Biophys. Acta 1749173 (2005).

[36] J. H. Roh, V. N. Novikov, R. B. Gregory R B, J. E. Curtis, Z. Chowdhuri, and A. P. Sokolov

Phys. Rev. Lett. 95038101 (2005).

[37] A. P. Sokolov, H. Grimm and R. Kahn, J. Chem. Phys. 1107053 (1999).

[38] J. Swenson, H. Jansson and R. Bergman, Phys. Rev. Lett. 96247802 (2006).

[39] K. L. Ngai, S. Capaccioli and N. Shinyashiki 1123826 (2008).

\section{Figure captions}

Figure 1. Incoherent elastic intensities, normalised with respect to the lowest temperature, integrated over a small $Q$-range $\left(0.4 \AA^{-1}<Q<1.0 \AA^{-1}\right)$, of MBP hydration water (full circles) and $\mathrm{MBP}(\mathrm{H})+\mathrm{D}_{2} \mathrm{O}$ (empty circles).

Figure 2. Mean square displacements vs. $T$ of MBP hydration water, as calculated from measurements on IN5 (full circles), on IN16 [32] (empty circles), and from molecular dynamics simulations [32] (stars), together with $\mathrm{MSD}$ of $\mathrm{MBP}(\mathrm{H})+\mathrm{D}_{2} \mathrm{O}$ (full squares) measured on IN5. The experimental MSD of hydration water were corrected for the contribution of exchangeable protein protons [see Eq. (1)]. It is worth of note that the MSD reported on Ref. [32] were calculated with the formula: $S_{\mathrm{H}_{2} \mathrm{O}}(Q, E \approx 0) \approx \exp \left(-\left\langle u^{2}\right\rangle Q^{2} / 6\right)$ then they have been rescaled by a factor of 6 for purpose of comparison with the present results.

Figure 3. MSD of $\mathrm{MBP}(\mathrm{H})+\mathrm{D}_{2} \mathrm{O}$ measured on IN5 (full squares) and on IN16 (empty triangles). 


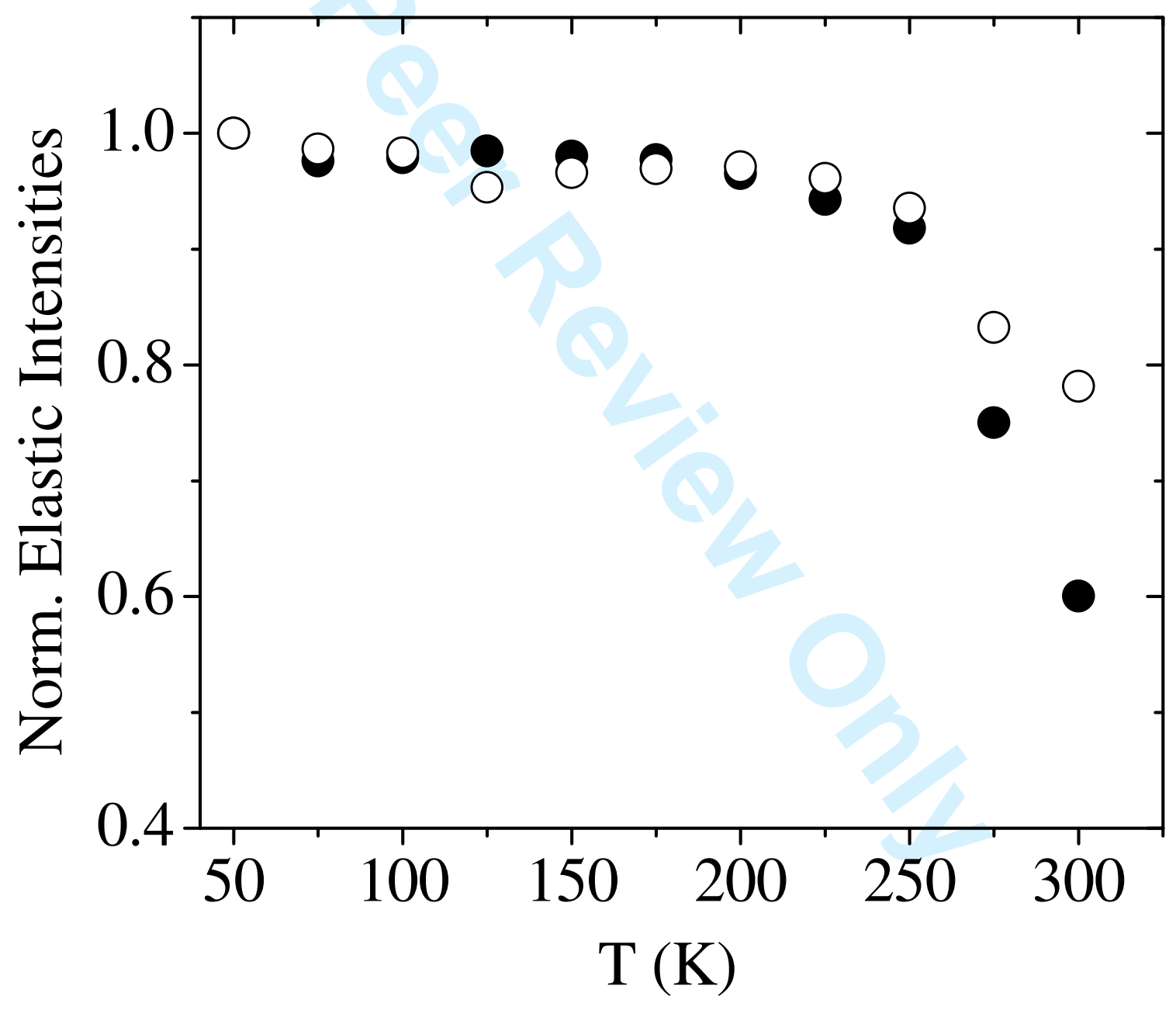

Figure 1. 


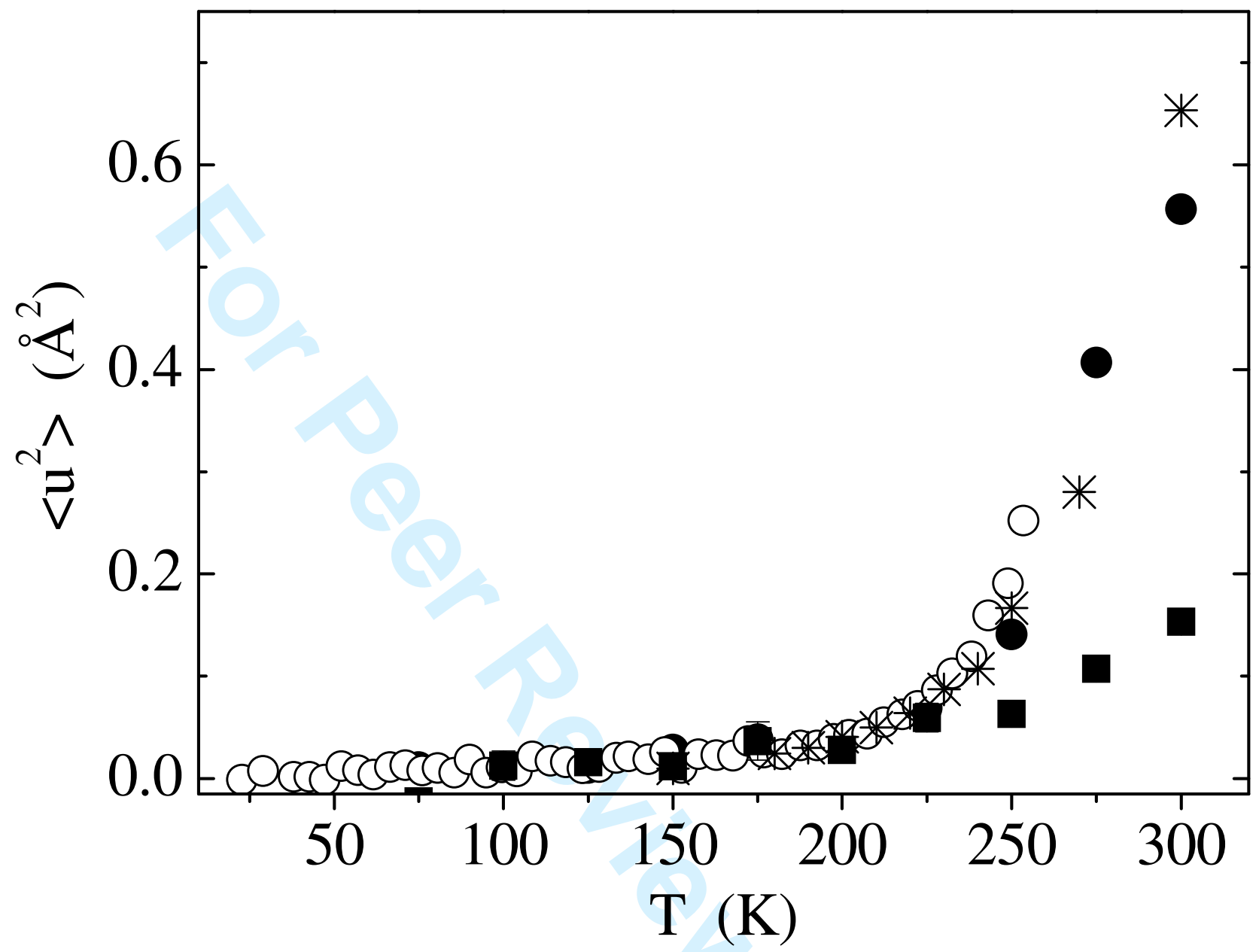

Figure 2. 


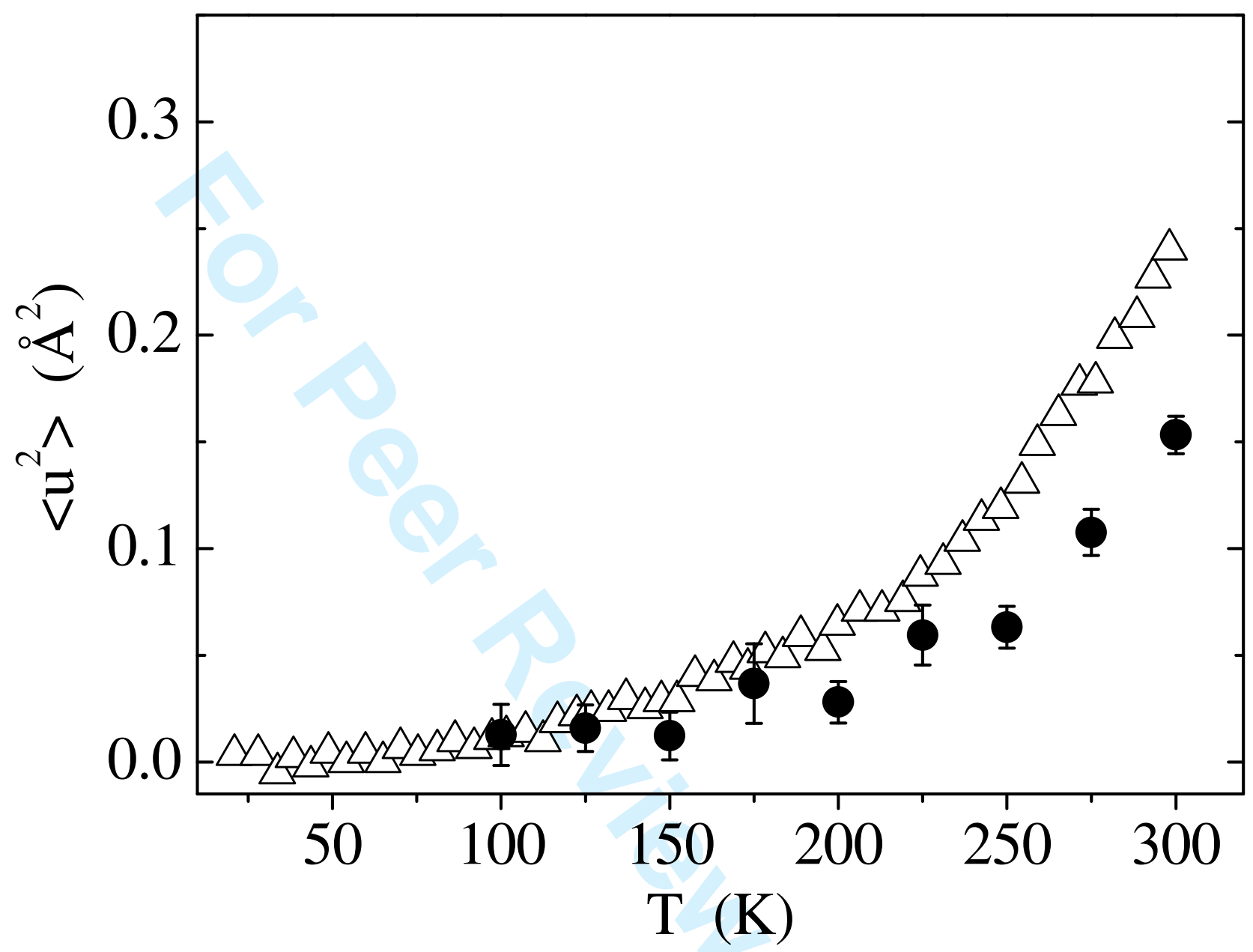

Figure 3. 